\title{
Complex characteristic for forecasting durability of hydraulic concrete
}

\author{
Valeriy Popov ${ }^{1}$, Dmitry Popov ${ }^{1}$, and Anna Davidenko, ${ }^{1, *}$ \\ ${ }^{1}$ Samara State Technical University, Academy of Architecture and Civil Engineering, \\ 443001, Samara, Molodogvardeyskaya Str., 194, Russia
}

\begin{abstract}
The paper analyzes operating conditions of hydraulic structures, as well as the main types of external influence with temperature and humidity variations. The purpose of the research is to highlight the main parameters which will be able to assess the actual durability of concrete hydraulic structures in the process of their design. The authors use methods developed in Samara Architecture and Civil Engineering Institute to determine concrete physical and mechanical characteristics. Thus, these methods help accurately assess concrete durability, frost resistance and water resistance. These methods are based on theoretical studies of the processes of concrete destruction by means of non-destructive acoustic methods. The the energy conception developed by A.A. Griffits and S.N. Zhurkova's kinetic serve as a scientific basis for the methods. Theoretical research and its analysis of concrete destruction processes from various kinds of external influence was confirmed by results of standard measurements. The research showed that durability of concrete, that is speed of its destruction, depended on two groups of physical and mechanical characteristics. One of the groups evaluates the initial structure of concrete, while the second group characterizes the speed of the material loading. The paper proposes a forecasting method of frost resistance and water-resisting properties of concrete according to its physical-mechanical characteristics. It also introduces an indicator of their assessment which is named the length of the reduced crack. The proposed indicator has a good correlation with frost resistance and water-resisting properties . Besides, the proposed method can be used not only in laboratory conditions, but also in construction production directly on the construction site.
\end{abstract}

\section{Introduction}

Most concrete structures operate under conditions of intensive environmental impact [1-5]. Effects on concrete structures can be mechanical, chemical, thermal, radiation, etc.Temperature variation during the year can vary widely over $1000 \mathrm{C}$, and humidity-from $0 \%$ to $100 \%$. In hydraulic structures, there is always a hydrostatic pressure [6], which leads to leaks in the concrete body. The task of the designers and manufacturers of concrete

\footnotetext{
*Corresponding author: aezg@mail.ru
} 
structures is the design and production of such concrete, which can be exploited in normative time without carrying out any activities on repair and the maintenance of stable working state structures.

\section{Materials and methods}

The target of determining the actual parameters of durability of concrete structures in the process of their design and manufacture is very relevant. For hydraulic engineering construction, such parameters include - frost resistance and water resistance of concrete.

The complexity of the task is due to the fact that the existing standard methods for determining the frost resistance and water resistance of concrete are very time-consuming, performed on bulky, energy-intensive equipment and only in the laboratory. To present time, there are no operational non-destructive methods for determining these characteristics, allowing in a short time directly in the design to find the quantitative values of the controlled characteristics. For many years, the Academy of construction and architecture of Samara state technical university has been developing operational methods for determining the values of physical and mechanical characteristics of various materials by acoustic methods [7-11], as well as methods and techniques for optimal design of building structures [12-26]. For concrete, the determination of frost resistance and water resistance are based on theoretical studies of the processes of destruction [27-30]. These theoretical studies of the energy concept and kinetic theory of fracture mechanics are based on the work of A. A. Gifits and S. N. Zhurkova [31, 33]. The developed methods of evaluation of physical and mechanical characteristics of concrete on the basis of ultrasonic studies are related to the methods of non-destructive testing [7-11, 27-30]. The theoretical studies of the processes of concrete destruction by various types of external influences (compression, tension, bending, cyclic freezing, hydrostatic action), confirmed experimentally, have shown that the rate of concrete destruction and its durability depend on two groups of characteristics.

The first group qualifies the initial structure of concrete and it includes surface energy, modulus of elasticity and Poisson's ratio. The second group characterizes the intensity of external action, i.e. the actual rate of loading of the material by force loads, low temperature or hydrostatic pressure. This group includes two kinetic characteristics: the propensity of concrete to crack formation and the intensity of crack formation. At the same time, for the first time in the practice of building science we used such characteristics of concrete as surface energy, which required the development of methods for its determination. The values of the modulus of elasticity and Poisson's ratio were determined by well-known methods that link these parameters of the material with the velocity of ultrasonic waves.

Attempts to develop methods for determining the kinetic characteristics of the processes of concrete destruction have not been successful, although work in this direction is quite intensive.

\section{Results}

In connection with this situation, one of the authors proposed a variant of forecasting the frost resistance and water resistance of concrete by the set of initial physical and mechanical characteristics, which are shown by the results of experimental studies, are sufficiently tightly correlated with the values of these characteristics obtained by standard methods in the laboratory [33]. This characteristic was called "reduced crack length" $\left(L_{r c}\right)$, it is energy-based and has a dimension in meters. For example, the following equation is 
proposed to determine the values of this parameter for concretes operating under cyclic low-temperature influence:

$$
L_{r c}=\frac{2 E v}{0.0225 \pi \mu^{2} R_{s}^{2}}
$$

where: $L_{r c}$ - length of the reduced crack, m;

$\mathrm{E}$ - modulus of elasticity, $\mathrm{MPa}$;

$\mu$-Poisson's ratio;

$v$ - surface energy,j;

$R_{s}$-compressive strength $\mathrm{MPa}$.

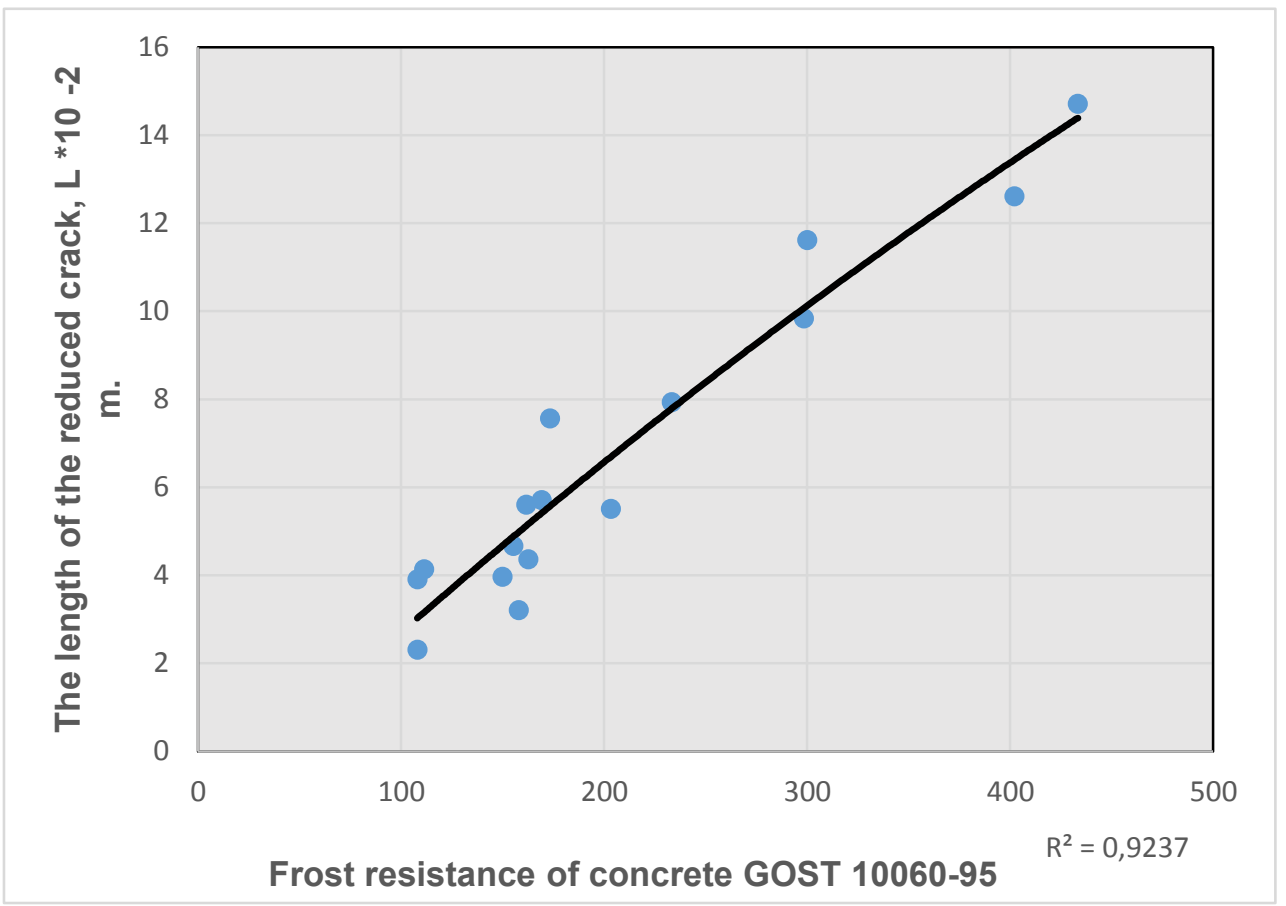

Fig. 1. Graph of the dependence of the length of the crack on frost resistance.

The correlation equation of the constructed dependence of the length of the reduced crack $\left(L_{r c}\right)$ on frost resistance $(F)$ has the following form:

$$
F=-15.23+2659 L_{r c}^{F}+4000\left(L_{r c}^{F}\right)^{2}
$$

with the correlation coefficient $\mathrm{R}=0.92$. A similar relationship is obtained between the water resistance and the length of the crack, with the value of the correlation coefficient equal to $R=0.89$.

The developed techniques can be applied not only in the laboratory, but on the construction site, in determining the values of the length of the crack directly in the erected structure. For this purpose, mass-produced ultrasonic devices with an oscillographic screen are used, and allow to measure the speed of the longitudinal and shear waves. According to the results of measuring the latter, the values of the elastic modulus and the Poisson's ratio are calculated by known methods. The values of surface energy directly in the structure can be measured by drilling, using reference samples, by the energy spent on drilling holes in 
concrete with pre-set parameters.

\section{Conclusion}

The method introduced by the authors for determining the parameters of frost resistance and water resistance of concrete, according to the integral characteristic - "length of the reduced crack", calculated by the values of the initial physical and mechanical characteristics of the concrete structure, allows you to quickly identify the quantitative characteristics of the durability of concrete directly in the structures on the construction site.

\section{References}

1. M.I. Balzannikov, I.S. Kholopov, Procedia Engineering 11, 72-81 (2015)

2. I.S. Kholopov, M.I. Balzannikov, Procedia Engineering 153, 277-282 (2016)

3. I.S. Kholopov, M.I. Balzannikov, etc., Bulletin of SSAUCE. Urban planning and architecture 28, 225 (2012)

4. M.I. Balzannikov, V.A. Zubkov, etc., Journal of Hydraulic Engineering 6, 21 (2013)

5. M.I. Balzannikov, V.A. Zubkov, etc., Power Technology and Engineering 4, 267-272 (2013)

6. I.S. Kholopov, A.O. Lukin, A.P. Litikov, Patent for utility model RUS 144738 04.14.2014

7. M.D. Mosesov, Traditions and innovations in construction and architecture. Building a collection of articles, 28-31 (2015)

8. M.D. Mosesov, Traditions and innovations in construction and architecture. Building a collection of articles, 51-54 (2016)

9. M.D. Mosesov, Traditions and innovations in construction and architecture. Building a collection of articles, 61-65 (2017)

10. V.A. Zubkov, N.V. Kondratieva, Patent for the invention RUS 226653323.03 .2004

11. V.A. Zubkov, I.V. Semerkov, E.V. Zubkov, Concrete and reinforced concrete 7, 9 (1993)

12. V.Yu. Alpatov, Patent for utility model RUS 111172 29.10.2009

13. A. A. Lukin, V.Yu. Alpatov, Science News of Eastern Technical Universities 3, 38-42 (2016)

14. A. A. Lukin, V.Yu. Alpatov, and etc., Bulletin of SASU 2 (23), 4-9 (2016)

15. A. A. Lukin, V.Yu. Alpatov, and etc., Construction. New technologies, new equipment 9, 52-55 (2016)

16. I.S. Kholopov, A.O. Lukin, et al., Building materials, equipment, technologies of the XXI century 12 (155), 40-45 (2011)

17. I.S. Kholopov, V.Yu. Alpatov, A.V. Soloviev, Science and Education in the 21 st Century. Collection of proceedings on the materials of the International Scientific and Practical Conference: in 34 parts, 145-147 (2013)

18. I.S. Kholopov, V.Yu. Alpatov, et al., Collection of reports of the scientific and practical conference dedicated to the 100th anniversary of Professor E.I. Beleni "Calculation and design of metal structures", 236-241 (2013)

19. V.Yu. Alpatov, A. A. Sakharov, and etc., MATEC Web Conf. 86, 02021 (2016) 
20. V.Yu. Alpatov, A. A. Lukin, Procedia Engineering 111, 20-29 (2015), ISSN 1877 7058

21. V.Yu. Alpatov, MATEC Web of Conferences 117, 00007 (2017)

22. V.Yu. Alpatov, S.M. Petrov, MATEC Web of Conferences 106, 04002 (2017)

23. V.Yu. Alpatov, O. Yu. Veremeenko, and etc., MATEC Web of Conferences 86, 02015 (2016)

24. V.Yu. Alpatov, MATEC Web of Conferences 86, 02005 (2016)

25. A. A. Lukin, and etc., Procedia Engineering 153, 414-418 (2016), ISSN 1877-7058

26. V.Yu. Alpatov, O.V. Alpatova, Scientific Review 24, 51-56 (2015)

27. V.P. Popov, Building Materials 8, 21-24 (1998)

28. V.P. Popov, S.F. Korenkova, D.V. Popov, University Bulletin. Construction 10, 3-6 (2010).

29. V.P. Popov, A.Yu. Davidenko, Building Materials 3, 5-9 (2012)

30. V.P. Popov, A.Yu. Davidenko, D.V. Popov, Materials of the 1st International Scientific and Practical Conference "Science and Education". Technical science, 18-20 (2014)

31. A.A. Griffith, Phil. Trans. Roy. Soc. Series, A-221, 163-198 (1921)

32. S.N. Zhurkov, Bulletin of the Academy of Sciences of the USSR 11, 78-82 (1957)

33. V.P. Popov, Thesis for a Candidate of Technical Sciences Degree (1986) 